\title{
RETERRITORIALIZAÇÃO E IDENTIDADE TERRITORIAL
}

\section{Reterritorialization and Territorial Identity}

\author{
Marcelo Cervo Chelotti \\ Professor Doutor do Instituto de Geografia da Universidade Federal de Uberlândia \\ Uberlândia/MG - Brasil \\ chelotti@ig.ufu.br
}

Artigo recebido para publicação em 10/07/2009 e aceito para publicação em 01/03/2010

RESUMO: $\quad$ Para realizar a referida análise, delimitamos o recorte temporal pós-1990 no qual se acentua a luta pela posse da terra no Rio Grande do Sul e, consequentemente, o processo de instalação dos projetos de assentamentos rurais na região. Assim, torna-se evidente uma nova dinâmica territorial em alguns municípios da Campanha Gaúcha, após o processo de reterritorialização camponesa. Nossa metodologia pautou-se na abordagem qualitativa. A partir dessa premissa, procuramos responder os objetivos propostos. No referencial teórico, discutimos a importância da incorporação do conceito de Territorialização-Desterritorialização-Reterritorialização (TDR) embasados nos estudos sobre as diferentes territorialidades promovidas pelos movimentos sociais no campo. Utilizamos também o conceito de identidade territorial, pois na análise em questão são conceitos que se complementam. Isso se justifica porque identificamos claramente duas identidades territoriais presentes nas expressões da reterritorialização camponesa na região. Detectamos que a configuração territorial da Campanha Gaúcha nesse início de século XXI é bastante complexa em função da heterogeneidade de atores envolvidos na trama territorial, apresentando-se como um espaço regional onde as rugosidades são evidentes, mas com transformações significativas em curso. Estamos, portanto, diante de uma nova territorialidade camponesa que expressa suas manifestações socioculturais por meio de elementos materiais e imateriais, promovendo uma metamorfose no espaço latifundiário regional. A partir dessas novas relações, os camponeses reterritorializados expressam nesse novo território sua identidade territorial.

Palavras-chave: Camponês. Latifúndio. Identidade Territorial. Reterritorialização. Espaço Agrário. Campanha Gaúcha.

ABSTRACT: In order to accomplish this analysis, the time focus is limited to after 1990, which highlights the struggle for the possession of land in Rio Grande do Sul, and consequently, the installation process of the projects of rural settlements in the region. Thus, a new territorial dynamics becomes evident in some boroughs of Campanha Gaúcha after the process of rural reterritorialization. Our methodology is guided in a qualitative approach. From that premise, we intend to meet the proposed objectives. In the theoretical framework we discuss the importance of incorporating the concept of Territorializationdeterritorialization-reterritorialization (TDR) in the studies on the different territorialities promoted by social movements in the countryside. We also use the concept of territorial identity, as in the referred analysis these are concepts which are complementary. This is justified because we clearly identified two territorial identities present in expressions of rural reterritorialization in the region. We have detected 
Reterritorialização e Identidade Territorial

Marcelo Cervo Chelotti

that the territorial configuration of Campanha Gaúcha in this beginning of the XXI century is quite complex due to the heterogeneity of the actors involved in the territorial plot, presenting itself as a regional space where roughness is evident, but with significant changes underway. Therefore, we are before a new rural territoriality which expresses its sociocultural manifestations through material and non-material elements, promoting a metamorphosis in the regional latifundiarian space. From these new relationships, the reterritorialized peasants express in this new territory their territorial identity.

Keywords: Peasant. Latifundia. Territorial Identity. Reterritorialization. Agrarian Space. Campanha Gaúcha.

\section{INTRODUÇÃO}

A Campanha Gaúcha, por várias décadas, constitui-se o principal território da pecuária de corte no estado do Rio Grande do Sul, principalmente, por ser uma expansão do bioma Pampa em território brasileiro. A paisagem formada por campos naturais, estâncias e modo de vida do gaúcho assegurou a essa região fronteiriça uma identidade singular em relação às demais regiões brasileiras.

Na década de 1990, na medida em que ocorreu a territorialização da luta pela terra na Campanha Gaúcha, evidenciamos que novos elementos socioculturais foram incorporados na questão regional, que historicamente constituiuse numa sociedade regional com forte identidade associada ao espaço latifundiário e seus elementos simbólicos.

Portanto, o presente artigo tem por objetivo aprofundar a discussão sobre os processos de reterritorialização camponesa em curso na Campanha Gaúcha, que estão permeados por uma forte manutenção da identidade territorial desses sujeitos da reforma agrária, que passaram a expressar no novo território, elementos socioculturais de seus antigos territórios de vida.

Para realizar a referida análise, delimitamos o recorte temporal pós-1990 no qual acentua-se a luta pela posse da terra no Rio Grande do Sul e, consequentemente, o processo de instalação dos projetos de assentamentos rurais na região. Assim, torna-se evidente uma nova dinâmica territorial presente em vários municípios da região promovida pela instalação de assentamentos rurais. Destacase, porém, que essa nova dinâmica ainda é pouco conhecida e investigada na esfera regional por ser um processo recente, ou seja, pós-1990.

No decorrer do processo de reterritorialização desses trabalhadores, seus espaços socioculturais foram recriados, embora, muitas vezes, distantes de suas regiões de origem. Nesse contexto, a territorialização da luta pela terra redefiniu o papel da agricultura familiar, fortalecendo-a em áreas típicas de pecuária de corte, e tem potencializado, embora timidamente, a diversificação da matriz produtiva regional, historicamente alicerçada na pecuária e no cultivo da lavoura orizícola.

\section{CONSIDERAÇÕES SOBRE DESTERRITO- RIALIZAÇÃO E IDENTIDADE TERRITORIAL}

O movimento de renovação da Geografia brasileira, que teve como marco temporal o ano de 1978, introduziu uma perspectiva mais crítica na análise da espacialidade dos fenômenos sociais. Assim, alguns conceitos trabalhados na Geografia ganharam maior evidência que outros, podendose citar o caso do território. Para Santos e Silveira (2002), o que interessa discutir é o território usado, sinônimo de espaço geográfico.

Assim, o que passou a interessar aos geógrafos foi o espaço geográfico, entendido como aquele espaço que é apropriado e utilizado pelo homem. O 
resultado dessa relação seria a "produção do espaço geográfico". Portanto, no espaço, as relações sociais se materializam e se reproduzem gerando territórios a partir das relações de poder.

Com o avanço do processo dominante de globalização generalizou-se um discurso de um mundo cada vez mais desenraizado, móvel, fluido (virtual) em detrimento de um mundo mais enraizado (territorial). Para Haesbaert (2002), o conceito de território é o mais difundido na Geografia e a maioria dos trabalhos focaliza sua destruição, ou seja, a desterritorialização, sem deixar claro que concepção de território encontra-se por trás deste processo.

Temos, então, dependendo da ênfase a um ou outro de seus aspectos, uma desterritorialização baseadanumaleituraeconômica(deslocalização), cartográfica (superação das distâncias), "técnico-informacional" (desmaterialização das conexões), política (superação das fronteiras políticas) e cultural (desenraizamento simbólico-cultural). Na verdade, parece claro, são processos concomitantes: a economia se multilocaliza, tentando superar o entrave distância, na medida em que se difundem conexões instantâneas que relativizam o controle físico das fronteiras politicas, promovendo, assim, um certo desenraizamento das pessoas em relação aos seus espaços imediatos de vida. Mas o que se vê, na realidade, são relações muito complexas. [...] A desterritorialização que ocorre numa escala geográfica geralmente implica uma reterritorialização em outra [...] (HAESBAERT, 2002, p. 132-3).

Estamos diante do que se denominou processos geográficos de TerritorializaçãoDesterritorialização-Reterritorialização (TDR), pois a criação de territórios seria representada pela territorialização, a sua destruição (por mais que seja temporária) pela desterritorialização, e pela sua recriação a partir de processos de reterritorialização.

Como exemplo desse processo geográfico de TDR, podemos citar o caso dos imigrantes italianos reterritorializados nas antigas áreas florestais do Rio grande do Sul. Em um primeiro momento, esses camponeses europeus foram desterritorializados em função do avanço da revolução industrial e num segundo momento, foram reterritorializados no sul do Brasil. Em decorrência do movimento da sociedade, seus descendentes foram desterritorializados com o advento da modernização da agricultura, e o processo de reterritorialização ocorrerá, por exemplo, na medida em que ingressaram e organizaram-se em movimentos sociais no final da década de 1970 .

Ao observarmos os recentes estudos no âmbito das Ciências Sociais e Humanas, verificaremos a utilização, com frequência, da terminologia desterritorialização e reterritorialização, seja em estudos sobre migração, luta pela terra, identidade territorial, dentre outros. No entanto, a utilização dessa terminologia é um pouco mais remota, encontrada principalmente na obra dos filósofos Deleuze e Guattari (1972). A principal contribuição dos autores é a de que não existe uma desterritorialização desconecta de uma posterior reterritorialização.

A função de desterritorialização: D é o movimento pelo qual "se" abandona o território. É a operação da linha de fuga. Porém, casos muito diferentes se apresentam. A D pode ser recoberta por uma reterritorialização que a compensa, com o que a linha de fuga permanece bloqueada; nesse sentido, podemos dizer que a D é negativa. Qualquer coisa pode fazer as vezes da reterritorialização, isto é, "valer pelo" território perdido; com efeito, a reterritorialização pode ser feita sobre um ser, sobre um objeto, sobre um livro, sobre um aparelho, sobre um sistema [...] (DELEUZE; GUATTARI, 1997, p. 224, grifo no original).

Abordar os conceitos de desterritorialização e reterritorialização a partir do discurso geográfico permite dotar a Geografia de um corpo teóricoconceitual renovado e necessário para entender a complexidade do mundo contemporâneo. Portanto, aí reside uma grande contribuição para nossa discussão. Para Haesbaert (2004), é necessário destacar a forte 
vinculação da obra dos autores com a Geografia, principalmente (mas não apenas) através do conceito de desterritorialização. Para o autor, devemos pensar a territorialização e a desterritorialização como processos concomitantes, ou seja, fundamentais para compreendermos as práticas humanas.

No entanto, não existe um consenso de que os processos de desterritorialização são precedidos de processos de reterritorialização. Assim, evidenciamos duas grandes correntes interpretativas, principalmente, associadas ao processo de globalização. Uma, que defende que a globalização estaria provocando desterritorialização e a outra, defendo que embora ocorra desterritorialização numa escala, se verifica reterritorialização em outra.

Dentre os trabalhos, podemos citar alguns, como Storper (1994), Ianni (1995), Andrade (2002), Neves (2002), Saquet (2003), Haesbaert (1997, 1999, 2001, 2002, 2004, 2006), Oliven (2006). Esses estudos ganharam vulto na década de 1990, quando o processo de globalização da economia mundial, configurou-se com um momento histórico importante do sistema capitalista que teve como uma de suas principais características o processo de desenraizamento, ou melhor, o processo de desterritorialização.

Para Ianni (1995), a globalização tende a desenraizar as coisas, as pessoas e as idéias. Tudo tende a desenraizar-se: mercadoria, mercado, moeda, capital, empresa, agência, gerência, projeto, publicidade, tecnologia. Para autor, assim, se desenvolve o novo e surpreendente processo de des-territorialização, uma característica essencial da sociedade global em formação.

O conceito de desterritorialização aplica-se não apenas a óbvios exemplos como corporações transnacionais e mercados monetários, mas também a grupos étnicos, lealdade ideológicas e movimentos políticos que atuam crescentemente em moldes que transcendem fronteiras e identidades territoriais especificas. A desterritorialização tem afetado as lealdades de grupos envolvidos em diásporas complexas, suas manipulações monetárias e outras formas de riqueza e investimento, bem como as estratégias de Estado. O debilitamento dos vínculos entre povo, riqueza e territórios, por sua vez, tem alterado a base de muitas interações globais significativas e, simultaneamente, põe em causa a definição tradicional de Estado. (IANNI, 1995, p. 93).

O processo de desterritorialização ocorre com múltiplas implicações, sejam nas esferas sociais, econômicas, políticas ou culturais. O mundo estaria cada vez menor, numa compressão nas relações espaço-tempo.

À primeira vista, a desterritorialização lança a idéia de sociedade global no cerne da pósmodernidade. Ai muita coisa muda de figura, desloca-se, flutua, adquire outro significado, dissolve-se. Ao lançar-se além dos territórios, fronteiras, sociedades nacionais, linguas, dialetos, bandeiras, moedas, hinos, aparatos estatais, regimes políticos, tradições, heróis, santos, monumentos, ruinas, a sociedade global desterritorializa tudo o que encontra pela frente. E o que se mantém territorializado já não é mais a mesma coisa, muda de aspecto, adquire outro significado, desfigura-se. Rompem-se os quadros geográficos e históricos prevalecentes de espaço e tempo. Emergem outras conotações para o que é singular, particular, universal, em outras mediações. (IANNI, 1995, p. 103-104, grifo no original).

O que verificamos, no entanto é, cada vez mais, o fortalecimento de barreiras/fronteiras. A sociedade global somente pode ser pensada na perspectiva da economia, mas, no plano político e cultural, verificamos a reafirmação de regionalismos e o impedimento de livre acesso das pessoas.

Só se pode compreender a globalização pela cuidadosa documentação dos casos em que ocorre a desterritorialização e daqueles em que a territorialização continua a exercer um

Sociedade \& Natureza, Uberlândia, 22 (1):165-180, abr. 2010 
forte papel; no primeiro caso, as atividades se tornam menos dependentes de recursos, práticas e interdependências especificas de um local. No segundo, continuam enraizadas em aspectos especificos locais. Só analisando os mutáveis e complexos padrões de territorialização e desterritorialização de atividades se pode desenhar um quadro preciso da natureza da globalização. (STORPER, 1994, p. 13, grifo no original).

No entanto, existe uma outra linha interpretativa que nega a análise isolada dos processos de desterritorialização, pois estes deveriam levar em consideração os processos de reterritorialização, uma vez que a globalização não pode ser compreendida apenas como um processo homogêneo, uniforme e unilateral, existindo outras esferas que carecem ser observadas na atual conjuntura da sociedade contemporânea.

Uma das mais importantes contribuições no campo da Geografia para entendermos que os processos de des-territorialização devem ser analisados considerando também os processos de reterritorialização, é encontrada em Haesbaert (1997), quando o autor estudou a formação de uma rede "gaúcha" nos cerrados do nordeste brasileiro.

Apesar de distinguirmos analiticamente território e rede, como já ressaltamos no capítulo anterior, estes encontram tão articulados quanto o processo contraditório de territorializaçãodesterritorialização que os produz. Desse modo, as redes não podem ser vistas apenas como "destruidoras de territórios": uma combinação articulada de redes, "malha", por exemplo, pode ser a base de um processo de (re)territorialização, ou seja, de formação de novos territórios. (HAESBAERT, 1997, p. 94).

Para Haesbaert (1999), virou moda afirmar que vivemos uma era dominada pela desterritorialização, confundindo-se, muitas vezes, o desaparecimento dos territórios com o simples debilitamento da mediação espacial nas relações sociais. Para o autor, os grupos sociais podem muito bem forjar territórios em que a dimensão simbólica se sobrepõe à dimensão mais concreta.

Diante da massa de despossuidos do planeta, em índices de desigualdade social e de exclusão cada vez mais violentos, o "apegar-se à terra", a reterritorialização é um processo que vem ganhando força. Ele se torna imprescindivel não somente como fonte de recursos para a sobrevivência física cotidiana mas também para a recriação de seus mitos, de suas divindades ou mesmo para manter viva a memória de seus mortos. (HAESBAERT, 1999, p. 185).

$\mathrm{Na}$ tentativa de sistematizar o discurso vigente de que a sociedade vive um período de desterritorialização, Haesbaert (2002) aponta cinco possíveis interpretações: a primeira, uma perspectiva mais economicista, defende a idéia de superação dos entraves locais ou de localização; a segunda, uma abordagem mais cartográfica em que ocorreria a superação do espaço pelo tempo, ou seja, um encurtamento de distâncias; uma terceira, em que as relações seriam mais imateriais que materiais; uma quarta, em que ocorreria um esvaziamento das fronteiras, permitindo o livre acesso; e a quinta, em que a perspectiva cultural, referência simbólica, perderia sentido e se transformaria em não-lugar.

No entanto, o que se observa na realidade socioespacial contemporânea são relações muito mais complexas.

A mundialização, paradoxalmente, tem alimentado também a retomada de localismos, regionalismos elou nacionalismos, muitas vezes retrógrados e espacialmente segregadores [...] a velocidade dos fluxos e a simultaneidade proporcionada pelo progresso técnico não implicam obrigatoriamente, a superação de uma reterritorialização diferenciadora $e$ ressingularizante. [...] A desterritorialização que ocorre em uma escala geográfica geralmente implica uma reterritorialização em outra escala [...] (HAESBAERT, 2002, p. 132-133). 
A discussão teórica sobre os processos de des-re-territorialização no âmbito da Geografia ainda carece de uma maior dedicação por parte dos pesquisadores, uma vez que utilizam a terminologia, sem um devido aprofundamento conceitual. Assim, é muito frutífero o diálogo com as Ciências Sociais, que buscam na Geografia uma compreensão da dimensão espacial da sociedade.

Os trabalhos que se dedicam ao estudo de processos de reterritorialização são tão diversos quanto às realidades socioespaciais. Assim, encontramos diversas abordagens para um mesmo processo, como aquelas que se dedicam a entender mais por uma vertente econômica, política ou cultural. Estudos sobre movimentos sociais no campo e na cidade, transposição geográfica de identidades culturais, dentre outros, são exemplos claros de que a reterritorialização está na ordem do dia. No entanto, todo processo de desterritorialização é procedido de uma reterritorialização, seja na dimensão econômica, política, ou cultural.

Desterritorialização, portanto, antes de significar desmaterialização, dissolução das distâncias, deslocalização de firmas ou debilitação dos controles fronteiriços, é um processo de exclusão social, ou melhor, de exclusão socioespacial. [...] Na sociedade contemporânea, com toda sua diversidade, não resta dúvida de que o processo de "exclusão", ou melhor, de precarização socioespacial, promovido por um sistema econômico altamente concentrador é o principal responsável pela desterritorialização. (HAESBAERT, 2006, p. 67).

Mais do que um eminente processo de desterritorialização em curso, evidenciamos na sociedade contemporânea um complexo mundo organizado por inúmeras "formas" de territórios, uma verdadeira multiterritorialidade quase que esquizofrênica. Estaríamos aí, diante do "mito" da desterritorialização.

[...] o que está dominando é a complexidade das reterritorializações, numa multiplicidade de territorialidades nuca antes vista, dos limites mais fechados e fixos da guetoificação e dos neoterritorialismos aos mais flexiveis $e$ efêmeros territórios-rede ou "multiterritórios" da globalização. Na verdade, seria mais correto afirmar que o grande dilema desse novo século será o da desigualdade entre as múltiplas velocidades, ritmos e níveis de des-re-territorialização, especialmente aquela entre a minoria que tem pleno acesso e usufrui dos territórios-rede capitalistas globais que asseguram sua multiterritorialidade, e a massa ou "aglomerados" crescentes de pessoas que vivem na mais precária territorialização ou, em outras palavras, mais incisivas, na mais violenta exclusão elou reclusão socioespacial. (HAESBAERT, 2004, p. 372).

Portanto, estamos diante de um processo ainda mais complexo que a des-re-territorialização. O que evidenciamos nos dias atuais são proliferações de múltiplos territórios, ou melhor dizendo, multiterritorialidades. O território além de sinônimo de poder, também, é sinônimo de diversidade. E é na diversidade dos territórios que se constroem novas geografias, muitas vezes, fazendo o percurso contrário dos interesses dos grupos historicamente hegemônicos.

$\mathrm{O}$ processo de reterritorialização de trabalhadores rurais sem-terra ocorrido no decorrer da década de 1990, aproximou duas identidades territoriais, associadas a dois processos distintos de acesso à terra no Rio Grande do Sul, produzindo espaços agrários distintos, tanto na esfera econômica (produção), quanto na cultural (identidade). Por isso, entendemos que o processo de reterritorialização ocorrido na Campanha Gaúcha, promoveu transformações no âmbito da questão regional, principalmente associada à identidade regional, ou melhor dizendo, proporcionou novas leituras sobre as mudanças identitárias a respeito do significado da Campanha Gaúcha nesse início de século XXI.

Nesse contexto, Corrêa (2001) levanta algumas questões, dentre elas, qual seria o significado, na década de 1990, de falar em

Sociedade \& Natureza, Uberlândia, 22 (1):165-180, abr. 2010 
Sertão, Agreste, Campanha Gaúcha. A questão regional identificada entre o embate do "velho" (a organização socioespacial preexistente) e o "novo" (novos elementos econômicos e culturais), que acaba levando ao desfazer da velha região e ao refazer de outra, nova, mas que contém traços da antiga.

No entanto, antes de adentrarmos na questão mais empírica do encontro das identidades territoriais camponesas no espaço agrário da Campanha Gaúcha, tecemos algumas considerações sobre a utilização do conceito de identidade territorial numa perspectiva geográfica, uma vez que o espaço agrário deve ser pensando para além da esfera econômica, incorporando novas dimensões interpretativas.

A identidade constitui um termo polissêmico, estando relacionado tanto ao indivíduo no âmbito pessoal, como também à relação do indivíduo com a coletividade. No entanto, a categoria de análise identidade, aparece sob vários enfoques, dependendo da matriz teórica na qual ela é abordada. A existência de inúmeras concepções é fruto da fragmentação do conhecimento, haja vista, que a categoria identidade é utilizada nos estudos da Psicologia, Antropologia, Sociologia, Filosofia, História e, mais recentemente na Geografia Humana.

Existe um consenso de que toda identidade é uma construção social. Assim, os diferentes grupos sociais, ao longo do tempo, criaram significados, construindo identidades, sejam elas vinculadas a uma determinada cultura, ideologia, religião, etnia, territorial, dentre outros.

Não é dificil concordar com o fato de que, do ponto de vista sociológico, toda e qualquer identidade é construida. A principal questão, na verdade, diz respeito a como, a partir de quê, por quem, e para quê isso acontece. A construção de identidades vale-se da matéria-prima fornecida pela história, geografia, biologia, instituições produtivas e reprodutivas, pela memória coletiva e por fantasias pessoais, pelos aparatos e de poder e revelações de cunho religioso. Porém, todos esses materiais são processados pelos indivíduos, grupos sociais e sociedades, que reorganizam seu significado em função de tendências sociais e projetos culturais enraizados e sua estrutura social, bem como em sua visão de tempo/espaço. (CASTELL, 1999, p. 23).

Outra premissa fundamental a ser considerada em relação à construção das identidades, é a questão de sua mutabilidade no tempo e no espaço, superando uma visão estanque e partindo para uma compreensão de sua transformação, para a destruição ou reafirmação, principalmente, em tempos de globalização.

A questão da identidade está sendo extensamente discutida na teoria social. Em essência, o argumento é o seguinte: as velhas identidades, que por tanto tempo estabilizaram o mundo social, estão em declínio, fazendo surgir novas identidades e fragmentando o individuo moderno, até então visto como um sujeito unificado. A assim chamada "crise de identidade" é vista como parte de um processo mais amplo de mudança, que está deslocando as estruturas e processos centrais das sociedades modernas abalando os quadros de referência que davam aos individuos uma ancoragem estável no mundo social. (HALL, 1998, p. 7).

A identidade é construída por subjetividades individuais e coletivas e pode estar relacionada a grupos sociais ou ao pertencimento territorial. Portanto, percebe-se que a incorporação da dimensão simbólica, do imaterial no discurso geográfico, tem possibilitado uma enorme riqueza nas análises sobre a produção do espaço, das paisagens, das territorialidades.

Abordar a questão da identidade em tempos de globalização, principalmente aquela relacionada com a perspectiva cultural exige algumas ressalvas sobre as transformações nas relações espaço-tempo, relativizando a questão da identidade, em decorrência dos crescentes processos homogeneizantes impostos pela globalização. A presença de identidades isoladas é cada vez mais relativa, em prol de situações mais integradas, interconectadas, ou híbridas. 
Hall (1998), ao discutir o aparente enfraquecimento das identidades nacionais frente ao processo globalizante, embora reconheça o seu enfraquecimento, ressalta que, na verdade, estaríamos diante de uma situação contraditória, uma vez não podemos negar o caráter homogeneizante da globalização, no entanto, seria muito reducionista imaginar que a destruição seja um processo dominante, pelo contrário, evidenciam-se novas identidades em curso.

As identidades nacionais estão se desintegrando, com resultado do crescimento da homogeneização cultural e do "pós-moderno global". As identidades nacionais e outras identidades "locais" ou particularistas estão sendo reforçadas pela resistência à globalização. As identidades nacionais estão em declínio, mas novas identidades - híbridas - estão tomando seu lugar. (HALL, 1998, p. 69).

Nessa mesma linha de raciocínio, Le Bossé (2004) também defende a idéia de que existe uma contradição sobre o impacto da globalização sobre as identidades culturais.

A questão parece particularmente apropriada no contexto contemporâneo da globalização e face a uma comprovação paradoxal: embora a diversidade das identidades culturais parecesse ameaçada de erosão pelo efeito de forças globais trazidas pela revolução das comunicações, ela persiste e se afirma às vezes vigorosamente nas escalas locais ou regionais. (LE BOSSÉ, 2004, p. 170).

Estamos, portanto, diante de um mundo que está conectado, principalmente, por um padrão de consumo uniformizante, retirando a exclusividade de determinadas identidades culturais que, cada vez mais, sofrem influências externas. Como exemplo, podemos citar o caso de certas comidas típicas que foram difundidas mundo a fora. Assim, seria muito reducionista dizer que determinada comida é exclusiva da tradição de um povo, quando ela passou a ser consumida nos quatro cantos do mundo.
Estamos diante de uma profunda relativização do conceito de identidade, pois devido ao avanço do processo de globalização encontra-se cada vez mais desvinculado de seus lugares, regiões, territórios históricos.

No outro extremo, porém, observamos o reforço de certas identidades locais como espaços de resistência frente à lógica global dominante. Para Hall (1998), trata-se do fortalecimento de identidades locais ou da produção de novas identidades.

Mesmo que o processo de globalização tenha avançado nos últimos anos, aprofundando a expansão do modo de produção capitalista, acelerando as trocas comerciais, acreditamos que existem elementos culturais que são preservados, mantidos, ou reinventados, principalmente, pelas chamadas populações tradicionais, podendo-se destacar o modo de vida camponês e seu universo simbólico que resiste a esse processo globalizante que insiste em destruir o diferente na tentativa de unificar tudo e a todos num único mercado global.

Muitos pensavam que a desaparição da maior parte dos traços que promoviam a infinita variedade do mundo tradicional pressagiava a erosão das diferenças culturais. $O$ que se descobre? Sociedades onde os problemas de identidades são mais envolventes do que nunca. É nesse paradoxo que é necessário compreender para vencer os desafios que nossas sociedades devem revelar no domínio da cultura. (CLAVAL, 2001, p. 385).

Reconhecendo que o processo de globalização não foi capaz de destruir certas características socioespaciais, principalmente, aquelas relacionadas aos aspectos culturais (materiais ou imateriais), evidenciamos, então, a permanência de elementos identificadores de identidades coletivas, principalmente em sociedades tradicionais (como a camponesa) que não se inseriram completamente na onda modernizante.

Acreditamos, então, que ocorre, embora 
de maneira relativizada, a identificação de certos grupos sociais com uma determinada espacialidade (território, região, lugar) e suas representações simbólicas. Portanto, estaríamos diante da resistência da identidade com perspectiva territorial, principalmente, ainda verificável em sociedades tradicionais que não foram destruídas.

Os espaços diferem de acordo com suas características materiais e imateriais, ou seja, os seus recursos biofísicos e humanos, relações sociais, modos de produção e a sua cultura. A partir de relações específicas com homem versus meio, as sociedades historicamente construíram identidades territoriais próprias, com seus signos, símbolos e pertencimentos.

Assim, o que nos interessa são as identidades coletivas na perspectiva territorial, construídas a partir do significado (objetivo e subjetivo) e sentimento de pertencimento que cada grupo social expressa numa determinada porção do espaço geográfico (região, lugar, território) produzindo a chamada identidade territorial.

Partimos do pressuposto geral de que toda identidade territorial é uma identidade social definida fundamentalmente através do território, ou seja, dentro de uma relação de apropriação que se dá tanto no campo das idéias quanto no da realidade concreta, o espaço geográfico constituindo assim parte fundamental dos processos de identificação social. [...] De forma muito genérica podemos afirmar que não há território sem algum tipo de identificação $e$ valoração simbólica (positiva ou negativa) do espaço pelos seus habitantes. (HAESBAERT, 1999, p. 172).
Em nossa análise empírica com os camponeses reterritorializados na Campanha Gaúcha identificamos, claramente, a presença de traços identitários relacionados com as identidades territoriais da "Campanha" e da "Colônia". É evidente que estamos tratando de "sociedades" com fortes laços com a tradição camponesa e, por isso, acreditamos que ocorra a manutenção de determinados elementos e características identitárias relacionadas a essa tradicionalidade. A análise seria bem diferente, se o trabalho estivesse voltado para sociedades mais complexas, como por exemplo, aquelas com forte urbanização e totalmente integradas nas teias da modernidade.

\section{A RETERRITORIALIZAÇÃO CAM- PONESA CONSTRUINDO NOVAS TERRITORIALIDADES NA CAMPANHA}

Os difíceis encontros entre duas sociedades rurais distintas, camponeses pecuaristas e camponeses agricultores, produziram identidades territoriais distintas no tempo e no espaço (QUADRO 1). Entendemos que esses difíceis encontros que ocorreram no decorrer do século XIX e no transcurso do XX, permaneceram latentes na virada para o século XXI, principalmente, na Campanha Gaúcha, devido ao processo de reterritorialização camponesa, "obrigando" os camponeses sem-terra a se defrontarem com uma nova identidade territorial, exigindo novas estratégias de sobrevivência, num território historicamente dominado pelo latifúndio pecuarista e seus elementos simbólicos e culturais. 
QUADRO 1: Modelo clássico da identidade territorial camponesa gaúcha. Org.: autor (2008)

\begin{tabular}{|c|c|c|}
\hline $\begin{array}{l}\text { IDENTIDADE } \\
\text { TERRITORIAL }\end{array}$ & $\begin{array}{c}\text { CAMPONESES DA } \\
\text { CAMPANHA }\end{array}$ & $\begin{array}{l}\text { CAMPONESES DA } \\
\text { COLÔNIA }\end{array}$ \\
\hline ORIGEM & $\begin{array}{l}\text { Surgiram no século XVIII, nas } \\
\text { bordas das primeiras estâncias como } \\
\text { agregados, desenvolvendo atividades } \\
\text { complementares à estância pastoril. } \\
\text { A posse da terra ocorreu por meio de } \\
\text { concessão. }\end{array}$ & $\begin{array}{l}\text { Surgiram no século XIX, nas áreas florestais } \\
\text { desprezadas pela atividade pastoril, devido } \\
\text { ao processo de colonização com imigrantes } \\
\text { europeus. A posse da terra ocorreu por meio } \\
\text { da aquisição da propriedade. }\end{array}$ \\
\hline ETNIA & $\begin{array}{l}\text { Sua descendência de origem é Luso- } \\
\text { brasileira, mas com presença de } \\
\text { mestiços, afro-brasileiros, hispanos e } \\
\text { indígenas. }\end{array}$ & $\begin{array}{l}\text { Sua descendência majoritária é ítalo- } \\
\text { germânica e, em menor, escala mestiços. }\end{array}$ \\
\hline MODO DE VIDA & $\begin{array}{l}\text { Estilo de vida campeiro, com casa de } \\
\text { torrão de barro coberta com capim. } \\
\text { Grande dispersão entre as residências. } \\
\text { Em função das longas distâncias, a } \\
\text { vida social comunitária centrava-se } \\
\text { em torno do Bolicho de campanha, no } \\
\text { jogo de taba, na corrida de cavalos. }\end{array}$ & $\begin{array}{l}\text { Estilo de vida colonial, com casa de madeira } \\
\text { ou pedra. As residências localizadas umas } \\
\text { próximas das outras, favorecendo a vida } \\
\text { social comunitária em torno da igreja } \\
\text { (católica ou protestante), e do salão de festas. }\end{array}$ \\
\hline PAISAGEM & $\begin{array}{l}\text { A campanha, uma extensão do } \\
\text { Pampa. Há um predomínio de um } \\
\text { relevo levemente ondulado para } \\
\text { plano (coxilhas), com pouca presença } \\
\text { de vegetação arbustiva, exceto nas } \\
\text { margens dos rios e sangas (riachos), } \\
\text { com predomínio de campos naturais. }\end{array}$ & $\begin{array}{l}\text { As colônias foram originalmente criadas nas } \\
\text { áreas do planalto basáltico (exceto algumas } \\
\text { no sul do estado), em áreas de escarpas, vales } \\
\text { abruptos, sendo a vegetação original formada } \\
\text { por floresta subtropical. }\end{array}$ \\
\hline AGROPECUÁRIA & $\begin{array}{l}\text { Historicamente, desenvolveram } \\
\text { a pecuária de corte extensiva, } \\
\text { principalmente, de bovinos e ovinos. } \\
\text { Portanto, são identificados como } \\
\text { camponeses pecuaristas. A agricultura } \\
\text { desempenhou papel secundário, } \\
\text { apenas para o suprimento da unidade } \\
\text { familiar. }\end{array}$ & $\begin{array}{l}\text { Historicamente, desenvolveram a policultura } \\
\text { e a criação de pequenos animais, como } \\
\text { aves e suínos. Em relação à pecuária alguns } \\
\text { dedicavam-se à produção de leite. Portanto, } \\
\text { são identificados como camponeses } \\
\text { agricultores policultores. }\end{array}$ \\
\hline
\end{tabular}

Reconhecemos que na contemporaneidade, tal diferenciação polarizada tenha que ser relativizada devido à integração territorial promovida pelo avanço das relações capitalistas no campo. Mas, entendemos que alguns elementos socioculturais são mantidos pelos camponeses, pois a modernização não foi um processo homogêneo, pelo contrário, ela atingiu apenas uma parcela dos camponeses, desterritorializando os demais. Com a mobilidade camponesa, principalmente, por causa da luta pela terra e a posterior reterritorialização, que ocorreu distante dos antigos territórios de vida dos assentados, traços socioculturais foram elementos que não se perdem nessa trajetória, pelo contrário, são marcas de resistência camponesa frente às diversidades para a sobrevivência e para sua reprodução social nos novos territórios de vida.

O camponês, quando perde sua referência anterior, ou seja, sua condição de pequeno proprietário, ou de arrendatário ou sua relação com a terra, sofre um processo de desterritorialização. $\mathrm{Na}$ 
medida em que vai se constituir um novo território este camponês passará por um novo processo de organização, mas ainda manifestará os seus jeitos, as práticas, as suas experiências acumuladas em sua história de vida. (MEDEIROS, 2006, p. 285).

Identificamos nos depoimentos dos camponeses sem-terra, uma questão bastante destacada foi a migração, pois eles são provenientes de outras regiões do Rio Grande do Sul e, numa menor escala, da própria Campanha. Entendemos que em termos socioculturais é um fator muito importante, tendo em vista que a identidade cultural do camponês da Campanha não é a mesma daqueles provenientes das áreas coloniais.

Evidenciamos, ao longo do trabalho, que a história de vida dos camponeses gaúchos não pode ser analisada sem se considerar os processos geográficos de territorialização-desterritorializaçãoreterritorialização (TDR), principalmente, quando analisamos os camponeses das regiões coloniais formadas a partir da imigração européia no decorrer do século XIX. A reterritorialização desses camponeses europeus imprimiu na paisagem agrária gaúcha elementos socioculturais associados aos seus antigos lugares, realizando uma transposição do modo de construir suas casas, louvar a Deus, hábitos alimentares, dentre outros.

Esses processos geográficos são importantes para compreendermos a mobilidade camponesa na contemporaneidade, que se apresenta muito dinâmica, principalmente, com a constituição dos movimentos sociais no campo, especialmente o MST no Rio Grande do Sul, que tem propiciado a esses camponeses descendentes de imigrantes (italianos e alemães) que mantenham viva a "saga" de seus antepassados, encontrando um território para viver com dignidade. Medeiros (2006), ao estudar a identidade dos camponeses gaúchos, identificou que:

São esses camponeses que hoje estão nos assentamentos que constituem estas comunidades simbólicas, o que pode explicar esta geração do sentimento de pertencimento na busca de novas raizes, na busca de sua reterritorialização. Criar uma identidade num espaço desconhecido, onde cada dia é um novo conhecer, exige desses agricultores um esforço que perpassa sua condição de camponês. Entre erros e acertos uma nova territorialidade vai sendo construida. Muitos abandonam, desistem, vão para outros luares, mas há aqueles que ficam, resistem e começam a construir um território no qual as marcas de sua história vão sendo fixadas como marcas de sua identidade. (MEDEIROS, 2006, p. 282-3).

O processo de reterritorialização camponesa na Campanha Gaúcha foi capaz de materializar, na típica paisagem regional, novos elementos socioculturais associados à identidade territorial camponesa das áreas coloniais do Rio Grande do Sul. Isso é comprovado, por exemplo, pelos pequenos elementos, como a manutenção do estilo arquitetônico da residência e pela preocupação com a questão paisagística do lote, como é o caso da presença dos jardins, traços comuns da identidade territorial de áreas coloniais.

$\mathrm{Na}$ medida em que ocorre o processo de reterritorialização, outros desafios entram em cena, principalmente aqueles associados às estratégias de reprodução da unidade familiar. Ao chegarem à área definitiva, tudo está para fazer, desde as instalações para moradia até aquelas associadas aos primeiros cultivos. Por serem áreas de campo nativo, não apresentam condições adequadas para instalar residências, torna-se necessário o plantio de árvores para proteger a residência e os pequenos animais das intempéries do tempo, sejam elas associadas ao calor ou ao frio.

Observamos a preocupação em cercar as residências com árvores, que geralmente são eucaliptos ou acácias, pois possuem um ciclo vegetativo rápido. Além da proteção, essas árvores também são utilizadas posteriormente para construção de cercados e como lenha para o fogão. Nas proximidades da residência também são desenvolvidos os pequenos cultivos e a criação de pequenos animais. Evidenciamos um significativo 
estranhamento dos recém chegados ao chegarem ao assentamento. Inicialmente, destacaram a paisagem como sendo muito diferente da região de onde provinham que, de certa maneira, representava uma sensação de liberdade, tendo em vista que os campos são tão abertos que se perdem de vista; onde residiam anteriormente, o relevo era mais ondulado e íngreme.

É evidente que as primeiras percepções se deram a partir da relação estabelecida com o meio. Muito se falou das características do clima, muito frio no inverno e calor intenso verão, seguido de um período de poucas chuvas. Evidenciamos que essa foi a primeira adaptação ocorrida. Assim, mudou-se a relação homem x meio, já que seus saberes ligados ao clima tiveram que ser reavaliados, como período de plantio que é diferente, o rigor do frio no inverno por ser campo aberto, e o déficit hídrico no verão que restringe o cultivo de certas lavouras.

Outro elemento importante que gerou enorme estranhamento foi o relativo isolamento geográfico do assentamento em relação à vida em comunidades, uma vez que o rural da Campanha é marcado pela baixa densidade demográfica e um número muito pequeno de comunidades rurais com uma vida social (igrejas, clubes, armazéns, campo de futebol, etc.). Esses sujeitos são provenientes de regiões onde a comunidade rural possui um certo nível de organização e articulação, típico das áreas de imigração no Rio Grande do Sul.

O encontro com uma nova realidade certamente provocará uma desterritorialização dos processos simbólicos, quebrando muitas vezes as coleções organizadas pelos sistemas culturais com novas ressignificações e redimensionamento dos objetos, coisas e comportamento e isso tudo certamente imbricado de conflitos. Ao partir, esse agricultor sem terra saiu de um universo que recebeu como herança ao nascer e que agora vai se confrontar com o que élhe dado nesse momento. O que ocorre aqui é um duplo processo inserido neste ato de sair e de chegar, pois, ao mesmo tempo em que expressa as ilusões daqueles que saem, expressa também o sofrimento daqueles que atravessam a fronteira do desconhecido. $E$ a partir de então que uma nova necessidade se impõe, ou seja, é preciso mudar o modo de ver o mundo externo dando espaço para o surgimento de novos valores que the orientarão e the permitirão organizar-se no novo ambiente. Neste preciso momento é fundamental contar com a cooperação de amigos e parentes, o que lhes dará uma segurança para viver em terra desconhecida. $O$ viver em grupo lhes permitirá um enraizamento não tão doloroso quanto foi o desenraizamento $e$, assim, a construção da sua identidade com o novo. (MEDEIROS, 2006, p. 283).

A incorporação de novos elementos culturais na paisagem do Pampa não se resume somente ao âmbito da vida privada da casa e do jardim, mas, também, na esfera do nível tecnológico. Os instrumentos de trabalho utilizados pelos camponeses anteriormente ao processo de desterritorialização, mas que também são reterritorializados na Campanha, reproduzem um padrão técnico típico das regiões coloniais, como o carroção, a trilhadeira e a tobata.

No entanto, isso não significa que, no novo território de vida, esses objetos desempenharão a função anterior, pois o processo de reterritorialização é realizado ao mesmo tempo com manutenções, e, também, adaptações ao novo meio. Podemos citar, como exemplo, a trilhadeira de grãos, que se encontra subutilizada, pois os camponeses não tiveram sucesso com o cultivo de lavouras, substituíramnas por outras atividades como a pecuária de leite, fruticultura, dentre outras. E outros instrumentos foram adaptados para novas funções, como a tobata que servia para transportar grãos, e que adquiriu importância para o transporte do leite até o tanque resfriador.

Enquanto o típico camponês da Campanha realiza sua atividade no campo, o camponês reterritorializado proveniente das regiões coloniais, dedica-se preferencialmente, principalmente nos primeiros anos de assentamento, ao cultivo de lavouras, reproduzindo sua maior característica em relação à exploração da terra que é a policultura.

Sociedade \& Natureza, Uberlândia, 22 (1):165-180, abr. 2010 
Tanto o camponês da campanha, quanto o da colônia usam chapéu, mas a diferença é que o segundo usa o de palha, um símbolo do colono no Rio Grande do Sul. Essa constatação sociocultural ficou evidente durante o trabalho de campo, quando presenciamos o cotidiano desses camponeses reterritorializados.

Outra questão que deve ser ressaltada, referese à nova racionalidade da pequena propriedade encontrada na região que, historicamente, desenvolve a pecuária de corte (bovinos e ovinos) e não uma produção leiteira. Parece uma contradição, pois a vegetação de campos nativos permite o desenvolvimento da pecuária leiteira, mas o que está em jogo é uma questão cultural dos tradicionais pequenos proprietários da região. Percebendo essa potencialidade, dos campos nativos, os assentados passaram a investir na pecuária leiteira como estratégia de reprodução.

O encontro dessas duas identidades territoriais está promovendo a construção de uma nova identidade territorial, agora muito mais híbrida, com elementos culturais tanto da colônia quanto da campanha. A nosso ver, o "sucesso", a permanência, a adaptação do camponês reterritorializado na Campanha Gaúcha, dependerá tanto de elementos objetivos, como apoio institucional, quanto de elementos subjetivos como a adaptação aos "costumes" do novo meio, frente a uma nova identidade territorial que se aproximou de suas vidas no processo de reterritorialização.

O MST, através da criação de assentamentos na metade sul está, portanto, se territorializando na área que historicamente foi domínio do latifúndio pecuarista gaúcho. Isso, sem dúvida, tem reflexos significativos na forma como os assentados vão orientar e organizar suas vidas, pois os mesmos terão de passar por todo um processo de readaptação a um espaço que para eles era até então desconhecido; onde provavelmente não poderão desenvolver os mesmos cultivos, nem terem as mesmas técnicas que herdaram de seus antepassados e que tão bem desenvolveram nas áreas de origem. (MEDEIROS, 2006, p. 286).
É evidente que não podemos realizar uma análise determinista desse processo, pois elementos como financiamento, custeio, assistência técnica, apoio institucional são fatores fundamentais no processo de reterritorialização camponesa. Reafirmamos que são elementos que não explicam isoladamente o "sucesso" dos camponeses, pois por trás disso tudo, existem elementos subjetivos que não podem ser desconsiderados nessa análise. A saudade, a distância dos familiares, o estranhamento em relação à cultura local, a nova paisagem e seu significado, tudo isso são elementos subjetivos que influenciam no "sucesso" da reterritorialização camponesa na região.

Somos favoráveis à premissa de que o futuro desses camponeses reterritorializados na Campanha Gaúcha estará alicerçado, cada vez mais, em experiências integradoras dessas duas identidades, pois (re)construirão, ao longo do tempo, uma identidade territorial mais híbrida, ora incorporando novos elementos, ora preservando outros. Deixando o romantismo um pouco de lado, acreditamos que nesse caso, o hibridismo cultural refletirá diretamente nas estratégias de reprodução desses camponeses em pleno território latifundiário.

\section{CONSIDERAÇÕES FINAIS}

Os processos geográficos de TerritorializaçãoDesterritorialização-Reterritorialização (T-D-R) apresentam-se como importante viés analítico para interpretarmos a atuação dos movimentos sociais no campo e a construção de novos territórios da produção camponesa. No caso específico da nossa pesquisa, evidenciamos os processos de T-D-R da seguinte maneira:

a) Territorialização camponesa: a formação e territorialização do campesinato gaúcho deu-se por duas grandes frentes no tempo e no espaço.

a.1) o camponês da campanha - surgiu a partir das atividades complementares à estância pecuarista, ocupando as margens do latifúndio gaúcho, ainda no período 
anterior ao cercamento dos campos. A sua territorialização ocorreu principalmente na Metade Sul do Rio Grande do Sul.

a.2) o camponês da colônia - surgiu com o processo de imigração européia (alemães e italianos) no século XIX, emergindo como um forte segmento de pequenos proprietários de terras. A sua territorialização ocorreu principalmente na Metade Norte do Rio Grande do Sul.

b) Desterritorialização camponesa: genericamente evidenciamos duas fazes distintas desse processo no tempo e no espaço.

b.1) Desterritorialização na Campanha: ocorreu com a lei de terras (1850) quando muito camponeses que viviam nas margens da estância foram expulsos por não comprovarem a titulação de suas terras. A partir daí, foram viver nas periferias das incipientes cidades da região, ou trabalhar como empregados na atividade agropecuária. Outro processo, porém, mais recente, foi o avanço da modernização da agricultura que ocupou significativas parcelas do território, gerando a expulsão desses indivíduos.

b.2) Desterritorialização na Colônia: ocorreu na medida em que os lotes coloniais (25 hectares) tornaram-se pequenos para a reprodução da família, obrigando os colonos a migrar e ocupar outras áreas. Com a industrialização, muitos camponeses transformaram-se em proletariados na cidade. Em outras regiões, foram o avanço da modernização e a construção de barragens hidrelétricas que desterritorializaram milhares de camponeses gaúchos.

c) Reterritorialização camponesa: é um processo que também ocorreu de maneira diferenciada no tempo e no espaço.

c.1) Camponeses da colônia: inicialmente reterritorializados nas novas áreas de colonização, no próprio Rio Grande do Sul, mas também no oeste catarinense, e sudoeste do Paraná, Mato Grosso do Sul, e assim por diante. No entanto, com o passar dos anos, muitos camponeses e seus descendentes decidiram não migrar, permanecendo próximos aos seus territórios de vida. Com a mobilização de setores progressistas da Igreja, de sindicatos e de alguns intelectuais ocorreu a mobilização camponesa para reivindicar sua reterritorialização nas proximidades de seus antigos territórios. Assim, os primeiros assentamentos rurais foram realizados nessas áreas. Mas com o passar do tempo, ocorreu um deslocamento geográfico desses projetos em direção à Campanha, obrigando esses indivíduos a migrarem para essa região.

c.2) Camponeses da campanha: diferentemente dos seus semelhantes das áreas coloniais, historicamente tornaramse proletariados nas periferias urbanas. No entanto, na década de 1990, com a territorialização da luta pela terra na região, o MST incentivou a participação desses indivíduos em suas mobilizações. A partir de então, muitos indivíduos começaram a participar da luta pela terra, até conquistarem um pedaço de terra na própria região.É por isso que nos primeiros projetos de assentamentos rurais realizados na região, não se observava a participação de trabalhadores sem-terra provenientes da própria Campanha Gaúcha, diferentemente dos mais recentes.

No entanto, gostaríamos de destacar que os processos geográficos de T-D-R não são estanques, pelo contrário, configuram-se como processos dinâmicos inerentes à própria sociedade. Assim, não significa que um trabalhador sem-terra assentado (reterritorializado) tenha encerrado esse processo. O que evidenciamos, durante a realização do trabalho de campo, é que muitos desistem do lote e tornamse novamente desterritorializados. Por isso, que os processos geográficos de T-D-R não são encarados como uma fórmula matemática, onde o somatório de fatores gera um resultado definitivo.

Os processos de T-D-R na reforma agrária envolvem dimensões materiais e imateriais. As 
dimensões materiais dizem respeito às questões de infraestrutura que geralmente são precárias, principalmente, nos primeiros anos de assentamento, associadas à falta de uma verdadeira política de extensão rural e financiamento para as atividades agropecuárias. No plano da dimensão imaterial, entram em cena aspectos culturais, como a questão da identidade territorial, onde falam mais alto os sentimentos de saudade em relação aos familiares, de estranhamento do novo lugar, isolamento geográfico, dentre outros.

\section{REFERÊNCIAS}

BERNARDES, N. Bases geográficas do povoamento do estado do Rio Grande do Sul. Ijuí: Ed. UNIJUÍ, 1997. (Coleção Ciências Sociais).

BRANCO, M. T. C. Jovens Sem-Terra: identidades em movimento. Curitiba: Ed. UFPR, 2003.

BRUM, A. J. Modernização da agricultura: trigo e soja. Petrópolis: Vozes, 1988.

CASTELL, M. O poder da identidade. (a era da informação: economia, sociedade e cultura). Tradução Klauss B. Gerhardt. Prefácio de Ruth C. L. Cardoso. São Paulo: Paz e Terra, v.2, 1999.

CLAVAL, P. A geografia cultural. Tradução de Luiz Pimenta e Margareth Pimenta. 2 ed. Florianópolis: Ed. da UFSC, 2001.

CHELOTTI, M. C. A instalação de assentamentos rurais e a inserção de novos agentes no espaço agrário do município de Sant'Ana do Livramento RS. 2003, 215f. Dissertação (Mestrado em Geografia) - Faculdade de Ciências e Tecnologia, Universidade Estadual Paulista, Presidente Prudente, 2003.

_. A estância metamorfoseou-se: (re) configurações territoriais e expressões da reterritorialização camponesa na Campanha Gaúcha (1990-2007). 2009, 288f. Tese (Doutorado em Geografia) - Instituto de Geografia, UFU, Uberlândia, 2009.
DELUEZE, G.; GUATTARI, F. Mil platôs capitalismo e esquizofrenia. Tradução Peter Pál Pelbart e Janice Caiafa. São Paulo: Ed. 34, v. 5, 1997.

FERNANDES, B. M. MST: formação e territorialização. 2. ed. São Paulo: HUCITEC, 1999.

HALL, S. A identidade cultural na pós-modernidade. Tradução Tomaz Tadeu da Silva e Guacira Lopes Louro. 2 ed. Rio de Janeiro: DP\&A, 1998.

HAESBAERT, R. $R S$ : latifúndio e identidade regional. Porto Alegre: Mercado Aberto, 1988.

Des-territorialização e identidade: a rede gaúcha no Nordeste. Niterói: Eduff, 1997.

. Identidades territoriais. In: ROSENDAHL, Z.; CORRÊA, R. L. (Org.) Manifestações da cultura no espaço. Rio de Janeiro: Eduerj, 1999. p. 169-190.

Desterritorialização: entre as redes e os aglomerados de exclusão. In: CASTRO, I. E. da; COSTA, P. C. da; CORRÊA, R. L. (Org.) Geografia: conceitos e temas. 3 ed. Rio de Janeiro: Bertrand Brasil, 2001. p. 165-205.

Territórios alternativos. Niterói: Eduff; São Paulo: Contexto, 2002.

.O mito da desterritorialização: do "fim dos territórios" à multiterritorialidade. Rio de Janeiro: Bertrand Brasil, 2004.

— Da desterritorialização à multiterritorialidade. In: ENCONTRO DOS GEÓGRAFOS DA AMÉRICA LATINA, 10, 2005, São Paulo. Anais... São Paulo: USP, 2005. p. 6774 -6792 .

Concepções de território para entender a desterritorialização. In: SANTOS, M. et al . Território, territórios: ensaios sobre ordenamento territorial. 2 ed. Rio de Janeiro: DP\&A, 2006. p. 4370. 
HEIDRICH, A. L. Além do latifúndio: geografia do interesse econômico gaúcho. Porto Alegre: Ed. UFRGS, 2000.

IANNI, O. A desterritorialização. In: . A sociedade global. Rio de Janeiro: Civilização Brasileira, 1995. p. 89-105.

LEBOSSÉ, M.Asquestões de identidade em geografia cultural - algumas concepções contemporâneas. In: CORRÊA, R. L.; ROSENDAHL, Z. (Org.) Paisagens, textos e identidade. Rio de Janeiro: Ed. UERJ, 2004. p. 157-179.

MEDEIROS, R. M. V. Camponeses, cultura e inovações. In: LEMOS, A. I. G.; ARROYO, M.; SILVEIRA, M. L. (Org.) América Latina: cidade, campo e turismo. Buenos Aires: CLACSO; São Paulo: USP, 2006. p. 281-293.

- Re-territorialização e identidade: o significado dos assentamentos para a economia dos municípios: os casos de Hulha Negra, Aceguá e Candiota na Campanha Gaúcha (RS). In: IX COLÓQUIO INTERNACIONAL DE GEOCRÍTICA, 2007. Porto Alegre: Anais... Porto Alegre: UFRGS, 2007. p. 1-17.

NAVARRO, Z.; MORAES, M. S.; MENEZES, R. Pequena história dos assentamentos rurais no Rio Grande do Sul: formação e desenvolvimento. In MEDEIROS, L.S.; LEITE, S. (Org.) A formação dos assentamentos rurais no Brasil: processos sociais e políticas públicas. Porte Alegre/Rio de Janeiro: Ed. UFRGS/CPDA, 1999. p. 19-68.

NEVES, G. R. Territorialidade, desterritorialidade, novas territorialidades (algumas notas). In: SANTOS, M.; SOUZA, M. A. A. de; SILVEIRA, M. L. (Org.) Território - globalização e fragmentação. 5 ed. São Paulo: AnnaBlume/HUCITEC, 2002. p. 270-282.

OLIVEN, R. G. Território, fronteiras e identidades. In: SCHULER, F.; BARCELLOS, M de A. (Org.) Fronteiras: arte e pensamento na época do multiculturalismo. Porto Alegre: Sulina, 2006. p. 157-166.
PÉBAYLE, R. A vida rural na Campanha RioGrandense. Boletim Geográfico, Rio de Janeiro, n. 207, p.18-32, 1968.

. Os difíceis encontros de duas sociedades rurais. Boletim Geográfico do RS, Porto Alegre, n.18, p.35-45, jan/dez. 1975.

Éleveurs et agriculteurs du Rio grande do Sul (Brésil) Lille. Université de Lille III, 1974. Resenha de Adyr Ap. Ballastreri Rodrigues. Disponível em: <www.ieb.usp.br/ieb/publicacoes/ revista $>$. Acesso em 03 jul. 2006.

RAFFESTIN, C. Por uma geografia do poder. Tradução Cecília França. São Paulo: Ática, 1993.

SANTOS, M. A metamorfose do espaço habitado: fundamentos teóricos e metodológicos da Geografia. São Paulo: HUCITEC, 1988.

SANTOS, M.; SILVEIRA, M. L. O Brasil: território e sociedade no início do século XXI. 4 ed.. Rio de Janeiro: Record, 2002.

SAQUET, M. A. Os tempos e os territórios da colonização italiana: o desenvolvimento econômico na Colônia Silveira Martins (RS). Porto Alegre: Edições Est, 2003.

- Abordagens e concepções de território.

São Paulo: Expressão Popular, 2007

STORPER, M. Territorialização numa economia global: possibilidades de desenvolvimento tecnológico, comercial e regional em economias subdesenvolvidas. In: LAVINAS, L.; CARLEIAL, L. M. da F.; NABUCO, M. R. (Org.) Integração, região e regionalismo. Rio de Janeiro: Bertrand Brasil, 1994, p.13-26. 